\title{
Trabalho docente, educação a distância e as TICs: entre a excitação e o sobretrabalho
}

\author{
Katia Morosov Alonso \\ Danilo Garcia Silva \\ Universidade Federal de Mato Grosso
}

\section{Resumo}

Este estudo discute indícios sobre transformações do trabalho docente quando do desenvolvimento de cursos em educação a distância, com uso mais intenso das tecnologias da informação e comunicação. Após levantamento sobre a produção na área, que indicou incidência de poucos estudos sobre a temática, procedeu-se à pesquisa, fundamentada em "estudo de caso", num curso de graduação que, por suas características, exigia processos de mediação e interação por meio de ambientes virtuais de aprendizagem. Isso influenciou as formas pelas quais professores e orientadores acadêmicos trabalhavam, repercutindo em suas práticas pedagógicas. Necessário, por conseguinte, rediscussão sobre o tema, tendo em vista constatações relacionadas ao sobretrabalho gerado nesse tipo de atuação docente.

Palavras-chave: Trabalho docente. Educação a distância. Ambientes virtuais de aprendizagem. Mediação e Interação. 


\section{Teaching work, distance education and ICT: between excitement and overwork}

This study discusses signs of transformation in teaching work during the implementation of distance education courses, with an increase in the use of information and communication technologies. After research revealed the existence of few studies related to this subject area, the case-study approach was used to collect data in an undergraduate course which, due to its characteristics, required mediation and interaction processes through a virtual learning environment. This influenced the ways in which professors and academic advisers worked, which was reflected in their educational practice. However, it is necessary to rediscuss the subject, considering findings related to overwork in this type of teaching activity.

Keywords: Teaching work. Distance Education. Virtual Learning. Environment. Mediation and Interaction.

\section{Trabajo docente, educación a distancia y las TIC: entre el entusiasmo y el exceso de trabajo}

El trabajo discute indicios sobre transformaciones de la labor docente en lo que concierne al desarrollo de cursos en educación a distancia con el uso más intenso de las tecnologías de la información y comunicación. Tras levantamiento sobre la producción en el área que indicó incidencia de pocos estudios sobre la temática, se desarrolló investigación fundamentada en "estudio de caso" en un curso de graduación que, por sus rasgos, exigía procesos de mediación e interacción por medio del ambientes virtuales de aprendizaje. Eso influenció las formas como el profesor y los orientadores académicos trabajaban, repercutiendo en sus prácticas pedagógicas. Sin embargo, se hace necesario volver a discutir la investigación, teniendo en cuenta constataciones relacionadas al trabajo sobresaliente generado en ese tipo de actuación docente.

Palabras-clave: Labor docente. Educación a distancia. Ambientes virtuales de aprendizaje. Mediación e interacción. 


\section{Introdução}

Muito se tem discutido sobre problemas e possibilidades de uso da Educação a Distância (EaD), principalmente com a crescente incorporação das tecnologias da informação e comunicação (TICs) "traduzidas" ou configuradas nos denominados ambientes virtuais de aprendizagem (AVAs). São vários os estudos direcionados, por exemplo, às experiências com AVA, demonstrando como poderiam ser eficazes nas aquisições dos alunos, como melhor utilizar seus recursos, ou suas disponibilidades técnicas (Silva, 2010). São, contudo, menos numerosos os estudos que tenham por objetivo refletir ou analisar o trabalho dos docentes quando associados ou integrados às denominadas equipes multiprofissionais que sustentam, ao menos no caso brasileiro, a oferta de cursos por meio da EaD (Mill, 2010). É discussão candente aquela sobre a natureza mesma do trabalho do docente quando da organização de sistemas nessa modalidade de ensino, destacando as que se reportam aos novos atores desse processo: os tutores. Assim a ideia de professor coletivo (Belloni, 1999), polidocência (Mill, 2010), são algumas das reflexões que se põem nesse contexto, vislumbrando transformações significativas nos saberes e fazeres da docência.

0 "silêncio" sobre essa dimensão de análise parece estar vinculado à forma pela qual a denominada modalidade de EaD chegou às instituições públicas de ensino superior: ou pela busca de novas alternativas de financiamentos, ou pela expansão desse nível de ensino, como apontado por Alonso. (2010)

Há uma lacuna que necessita ser preenchida quando se problematiza o trabalho docente no desenvolvimento da EaD. Não se trataria de caracterizar, como faz Mill (2010), implicações trabalhistas, por exemplo, considerando os vários profissionais vinculados ao desenvolvimento dessa modalidade, nem de trazer à cena as formas pelas quais os "arranjos" têm ocorrido, especialmente nas instituições federais de ensino superior (Ifes), pelo "acomodamento" da sobrecarga de trabalho dos envolvidos nos programas de EaD com o pagamento de bolsas, incluindo aí o trabalho dos denominados tutores. As questões que se põem são: de que forma o trabalho do docente com a EaD, e com o uso mais intenso das TICs por conta dos AVAs, reflete outras e novas práticas pedagógicas? Ou isso seria uma ilusão? Afinal, em que tem redundado a entronização de equipamentos informáticos, a conexão em rede nas instituições que se propuseram ofertar cursos com a EaD? Que implicações teriam nas práticas pedagógicas dos professores que atuam com estes recursos? Responder a tais questões seria um passo importante para se compreender melhor seus reflexos na criação e permanência de contextos possíveis de serem observados nos cotidianos institucionais. Os professores têm respondido, por bem ou por mal, ao que se tem ofertado por meio da EaD, no entanto não lhes foi perguntado, ainda, sobre como estas respostas se constituíram ao longo desse trabalho.

0 presente artigo expõe resultados de pesquisa com foco no uso de AVA pelos 
envolvidos em processo de formação, explorando a dimensão do trabalho docente quando do uso mais intenso das TICs. Alguns indícios são possíveis de serem já observados: há mudanças nas práticas pedagógicas quando são instaurados processos mais intensos de uso das TICs e quando são conformadas propostas em que a mediação, a interação e a interatividade ocorrem; são apontadas algumas pistas da sobrecarga de trabalho gerada pela incorporação destas tecnologias; e, mais amiúde, há a necessidade de que o sobretrabalho, incluindo o do tutor, seja de fato entendido como resultado de novas experimentações.

Significativo igualmente considerar que a problemática que envolve o trabalho do docente na EaD, e por consequência o uso mais intenso das TICs, não poderia vir dissociada, quer de uma análise mais ampla sobre ele, quer de outra mais geral, implicando pensar a categoria trabalho nas denominadas "sociedades tecnológicas", como definido por Tezanos (2009). Para este pesquisador, independentemente da natureza do trabalho que se realiza, ele - trabalho - é intensificado quando as TICs são utilizadas largamente, isso como consequência dos novos domínios técnicos e psicológicos necessários para decodificá-las de modo a conviver com o caráter mutante desse novo trabalho.

Por outro lado, Türcke (2010), ao analisar a sociedade contemporânea, o faz tomando como referencial a ideia da sensação como compulsão repetitiva que se multiplica por meio dos aparatos tecnológicos, especialmente os audiovisuais, que reclama por estímulos imagéticos e sonoros na construção de identidades. A busca incessante destes estímulos intensifica a ilusão de "vivencias", transformadas num moto-contínuo de experiências. No caso do trabalho docente com o uso das TICs, o que se observa é que a ideia de se criar e recriar outro espaço educativo, constituído de novas linguagens que não o comum da sala de aula, é entendido como o de uma nova ordem, esta de caráter mais experimental e autônoma, portanto. Essas são evidencias e aproximações importantes da pesquisa no sentido de se compreender melhor a continuação de um labor que, mesmo exposto a uma sobrecarga razoável de atividades, é percebido como inovador.

0 trabalho traz ainda levantamento sobre estudos da EaD e TIC, apresentando pesquisa com base em estudo de caso que analisa, fundamentado em observações de "relatórios de atividades" dispostos em um AVA, indicativos de participação de alunos, professores e orientadores acadêmicos (OAs) em curso de pedagogia desenvolvido por meio de EaD.

0 termo "relatórios de atividades" é utilizado para designar o conjunto de recursos do ambiente Moodle, que armazena informações de acesso e de utilização dos recursos de interação e comunicação e dos materiais presentes no curso, os quais são disponibilizados aos atores do processo de formação. Esses relatórios, empregados pedagogicamente, poderiam contribuir para visualizar informações, avaliar e definir estratégias, melhorar a excelência da realização de determinadas atividades e acompanhar o processo de aprendizagem dos alunos. Essas informações são, em geral, relativas a cada participante ou ao curso ou 
turma.

Por ser um curso bastante peculiar em sua oferta, exigindo uso bastante intensificado de recursos comunicacionais dispostos pelas TICs, buscaram-se, então, nos registros dos relatórios de atividades, os professores especialistas (PEs) e orientadores acadêmicos (OAs) com maiores e menores índices de participação na formação de determinada área de conhecimento que compunha o curso analisado. Em seguida, a pesquisa esteve focada em como esses profissionais entendiam o trabalho docente nas condições postas no caso em questão. Os procedimentos e análises possíveis de serem encaminhadas até o momento são, assim, as que dão escopo e conteúdo ao texto a seguir.

\section{Sobre a EaD, alguns de seus dilemas e a problematização de um caso}

Interessante observar as discussões sobre o uso da EaD nos processos de formação: ora são ampliados seus poderes, no sentido de um uso que a tudo resolveria, ora são reforçados os perigos que rondam a qualidade do ensino quando da oferta de cursos nessa modalidade (Alonso, 2010). Para além dos polos tensionados revelados nessas duas posições, outro fator que interfere muito no debate sobre a EaD tem a ver com o uso mais intenso de TIC, redundando, inclusive, na ideia de que este seria um campo específico do não presencial - é frequente tomá-los como sinônimos. Tanto é assim que a maioria dos estudos relacionados ao tema apresenta um viés que reduz muito outros olhares sobre o uso da EaD e das TICs nos processos educativos. Em levantamento realizado em periódicos disponíveis no portal da Coordenação de Aperfeiçoamento de Pessoal de Nível Superior (Capes), no mês de novembro de 2010, quando utilizados descritores como "educação a distância" e "formação", por exemplo, poucos foram os trabalhos relacionados. Por outro lado, quando indicado "professores" e "TIC" apareceram 32 com prevalência na área da saúde; com o uso de "internet" e "professores" foi verificada, porém, a ocorrência de 984. Na leitura dos resumos, observou-se que mais da metade tratava de experiências com uso de AVA em cursos de EaD, enquanto os demais se dividiram entre análises de experiências bastante fragmentadas em relação ao uso das TICs em escolas e iniciativas de uso dessas tecnologias para portadores de necessidades especiais, sobretudo cegos e surdos. Não é à toa que, quando da referência sobre o uso das TICs nos processos educativos, quase sempre o campo se restringe à EaD, causando, sem dúvida, a percepção de que esses âmbitos se confundiriam, reduzindo a compreensão sobre uma problemática mais ampla e eivada de aspectos ainda pouco conhecidos, como é o caso das TICs nos processos educativos.

Mesmo com o "senão" antes mencionado, é crescente o uso dos denominados 
AVAs na formação por meio da EaD. A perspectiva é a de que os AVAs apoiariam diferentes organizações do ensinar e aprender, flexibilizando percursos e trajetórias de estudos, podendo suportar, simultaneamente, diferentes modelos pedagógicos e perfis de alunos. Nesses espaços, seria possível trabalhar com a criação, a atualização, o armazenamento, a recuperação, a distribuição e 0 compartilhamento instantâneo de informação em diversos formatos e mídias. (Schlemmer, 2005)

Embora essas vantagens estejam presentes na utilização de AVA, existe, por outro lado, limitações flagrantes no labor cotidiano com eles; há muito que se aprender nesse sentido (Silva; Alonso; Maciel, 2012). De toda maneira, necessário reconhecer as funcionalidades de tais ambientes: há vantagens e desvantagens nos distintos sistemas com os quais as instituições vêm trabalhando.

No caso brasileiro, o denominado Modular Object-Oriented Dynamic Learning Environment (Moodle) tem sido utilizado por grande parte das instituições públicas de ensino superior (Ipes), por se tratar de sistema com código aberto e permitir customização em seu uso. Além disso, é possível, por meio de “relatórios de atividades" próprios ao sistema, acompanhar o trabalho de alunos, professores e tutores, em que é factível verificar frequência, utilização de recursos e materiais disponibilizados no ambiente.

No contexto deste trabalho, entende-se que as possibilidades de interação envolvem todas as maneiras possíveis de comunicação, troca de informação e conhecimentos existentes em um AVA, compreendendo os "espaços" em que ocorrem: fóruns, chats, troca de mensagens, wikis, entre os principais recursos disponíveis. Isso requer, porém, novas e outras práticas pedagógicas, além da exigência de se efetivar processo de trabalho que redunde em participação e interação dos envolvidos na formação. É justamente aqui que os problemas do acompanhamento começam a surgir. Por mais indicadores que os AVAs, e mais particularmente o Moodle, por seu uso corrente nas Ipes, possam fornecer, permanece a questão sobre como isso afeta o trabalho da formação e, sobretudo, daqueles que aí atuam como docentes.

Os AVAs, como sistemas de comunicação que se fundamentam nas TICs, são recursos que visam aperfeiçoar a mediação do processo educativo. Analisar, então, o uso dos recursos de interação e de comunicação presentes nesses ambientes é fundamental para a melhor compreensão da formação mediada por tecnologias.

Há que se ressaltar, por fim, que a comunicação e a interação em contextos mediatizados por AVA, que se apresentam com a utilização de e-mail, fóruns, chat, webconferência, videoconferência, entre outros, vão além de meros estímulos para relações entre pessoas próximas e/ou distantes geograficamente. Nesse sentido, tais recursos ampliariam formas de pensar e de se relacionar socialmente, implicando outras maneiras de trabalhar com a informação e o conhecimento, como apontado por Santaella (2004); favorecendo a aprendizagem numa perspectiva de maior participação, interação e interatividade, e requerendo, pois, processos de 
mediação qualitativamente diferenciados e intensificados.

Diante do exposto, o presente estudo propõe-se a analisar a maneira pela qual é afetado o trabalho docente quando do uso do Moodle, de modo que essa problemática seja considerada quando da organização dos processos de ensino e aprendizagem que se utilizam de AVAs e TICs para mediação entre os atores, ou partícipes, de uma determinada proposta de curso.

Antes de dar sequência ao que será apresentado, importante destacar que, no presente artigo, e considerando o trabalho realizado pelos tutores na formação que se utiliza da EaD em seu desenvolvimento, compreende-se a atuação deste profissional como de natureza docente. Por mais que se afirme, como nos documentos que dão base à organização de sistemas de $\mathrm{EaD}$, com ênfase para os Referenciais de Qualidade para Educação Superior a Distância, que caberia aos tutores um papel de acompanhamento do aluno preferencialmente ao do "docente", o que se tem percebido, de fato, é sua responsabilização pelos processos de ensino (Alonso, 2010), incidindo em flagrante fator de desqualificação desses profissionais, inclusive a relacionada à forma pela qual são contratados pelas instituições. Embora o foco da pesquisa não tenha sido esse, a referência à problemática é importante, na medida em que a crescente oferta de vagas via EaD expõe a necessidade de esclarecer não só o papel profissional dos tutores, como também a ordenação de vínculos empregatícios que releve a real e concreta atuação deles.

Com relação ao curso em que a pesquisa foi realizada, não existe a figura de um tutor, os profissionais que atuam juntamente com os professores são denominados "orientadores acadêmicos" (OAs). O projeto político pedagógico (PPP) do curso em que ocorreu a pesquisa presume o OA como profissional que acompanha o aluno durante seus estudos. Sua função equivaleria, em parte, à do tutor, embora sua atuação fosse mais extensa, na medida em que, junto com os professores e sob a coordenação destes, participava do processo de avaliação da aprendizagem.

A proposta foi a de buscar alguns referenciais que indicassem a maneira pela qual é afetado o trabalho docente quando do uso mais intenso das TICs. Com base nos dados dos "relatórios de atividades" do Moodle, buscou-se identificar relações estabelecidas no ambiente, com relevância para os recursos de interação e de comunicação entre os sujeitos da formação.

As informações armazenadas pelos "relatórios de atividades" possibilitam identificar inúmeras informações sobre os participantes, tais como: quando e quantas vezes tiveram acesso ao ambiente, entre outros dados relevantes. A ideia era de que a análise dos dados presentes nesse recurso contribuiria para - acompanhamento da participação dos sujeitos envolvidos no processo da formação.

Esses relatórios estão disponíveis para o conjunto dos sujeitos que participam de um curso e são acessíveis por meio do "perfil dos participantes". O Moodle trata por participante aquele cadastrado no ambiente com participação num curso. Os 
"relatórios de atividades" são a eles inerentes, desde que habilitados para cada um dos cursos que o Moodle hospede e para cada um dos seus partícipes, incluindo os alunos.

\section{Da pesquisa: desenvolvimento, lugar e sujeitos}

Com base nas observações aqui expostas, a pesquisa teve por foco uma análise dos denominados "relatórios de atividades" do ambiente Moodle para que, por meio deles, considerando a participação e interação, fosse possível evidenciar indicadores de transformações e de como é afetado o trabalho docente em processos de formação mediatizados por TICs e AVAs.

Por mais que tais relatórios revelassem acessos, entradas e saídas, realização de atividades, postagens de materiais, etc., o caráter quantitativo que os definia deixava pouca margem para interpretá-los qualitativamente. Neste caso, foram tomados como indicadores aspectos relacionados à participação e à interação, cumprindo os objetivos pertinentes ao Moodle e ao curso pesquisado. A ideia foi a de que essas informações pudessem subsidiar a quantificação do trabalho docente realizado para que, posteriormente, e com base em outros instrumentos, fosse discutida a forma pela qual o afetariam.

O lócus da pesquisa foi o curso de pedagogia Acordo Brasil/Japão - modalidade a distância, desenvolvido pela Universidade Federal de Mato Grosso (UFMT) em parceria com a Universidade Tokai/Japão'. A escolha do curso teve por base o grande número de horas em que o trabalho da formação realiza-se no ambiente Moodle. Em razão da distância geográfica, fuso horário e estrutura do curso, a maior parte da comunicação e do trabalho pedagógico centra-se nas atividades nele organizadas.

0 projeto visava capacitar futuros professores/gestores que atuavam com crianças brasileiras no Japão, em escolas brasileiras lá instaladas ou em outros espaços educativos, formais ou não, que atendem, segundo a Associação de Escolas Brasileiras no Japão (AEBJ), em sua maioria, crianças da educação infantil e anos iniciais do ensino fundamental em período integral, das segundas-feiras aos sábados, para que os pais possam trabalhar. Tais profissionais, em grande parte, não têm formação ou, quando as têm, não são em licenciaturas.

0 curso de pedagogia Acordo Brasil/Japão surgiu com a proposta de reconhecer o trabalho das 72 escolas brasileiras, segundo dados de 2010, que, conforme constatado pela Embaixada brasileira em Tóquio, bem como pelo Ministério da Educação do Brasil (MEC), estão à margem do sistema educacional japonês.

1. A Universidade Tokai responsabilizou-se pela coordenação do curso no Japão e pela instalação de um sistema de educação a distância em seis polos de apoio presencial nos municípios japoneses: Ota, Hamamatsu, Nagoia, Kani, Hikone e Chino, destinados ao atendimento dos alunos. 
A concepção do curso foi pautada na experiência do Núcleo de Educação Aberta e a Distância (Nead) do Instituto de Educação (IE) da Universidade Federal de Mato Grosso (UFMT). Pelo histórico dessa instituição na formação de professores, em especial na formação de pedagogos, o Nead foi chamado para atender à demanda do MEC e da Secretaria de Educação a Distância (Seed), por intermédio da Universidade Aberta do Brasil (UAB), para a formação desses professores brasileiros no Japão.

Os recursos didáticos previstos para a formação apoiaram-se na utilização de diferentes mídias para a veiculação de conteúdos impressos ou em suporte digital (PPP, 2009). 0 AVA Moodle foi especificamente customizado para atender aos alunos. Igualmente, foram previstos encontros "presenciais" síncronos por meio de videoconferência; e, ao final de cada semestre, encontros presenciais entre alunos e professores para apresentação dos estudos relacionados às denominadas práticas educativas/seminários temáticos e estágios.

Dos 300 alunos matriculados atualmente, o curso conta com um total de 270 alunos. A desistência de 30 deles deu-se em razão da crise econômica vivida pelo Japão, que afetou, direta e intensamente, os trabalhadores brasileiros quando do terremoto seguido de tsunami e do acidente nuclear na usina de Fukushima. Parte considerável dos alunos, na situação de desemprego, optou por retornar ao Brasil. Quando questionados sobre o motivo da desistência, todos responderam que a falta de trabalho, no caso dos professores, com o fechamento de várias escolas, redundou no abandono. 0 curso jamais foi motivo de insatisfação para aqueles que não prosseguiram com os estudos, conforme constatado por Covezzi; Oliveira e Santos. (2011)

Pelo fato de 32 alunos terem retornado ao Brasil - pelos motivos expostos - e por já terem cumprido mais de $50 \%$ do currículo do curso, optou-se por abrir o polo Cuiabá de maneira que o trabalho de formação fosse continuado. Assim, mantiveram-se na formação via Moodle e encontros presenciais na UFMT, campus Cuiabá.

A equipe pedagógica do curso era composta por 17 OAs, que trabalhavam na UFMT: 15 deles vinculados às 15 turmas do curso, atendendo no máximo 20 alunos. Havia também um coordenador da orientação e outro que atendia aos alunos com atividades em atraso. A seleção destes profissionais se deu por meio de edital, com previsão de 30 horas semanais de trabalho. Do total dos OAs, todos tinham formação na área das licenciaturas, 3 possuíam especialização, 13, mestrado, e uma delas era doutoranda. Doze desses profissionais tinham experiência de, no mínimo, dez anos como professores da rede pública de ensino; 8 também possuíam alguma vivencia no ensino superior e 4 na EaD. Como OAs, receberam formação sobre a modalidade de EaD e sobre cada uma das áreas de conhecimento com que trabalhavam, contabilizando 20 horas, em média, de formação mensais.

De acordo com o PPP do curso, os professores especialistas tinham por atribuição desenvolver desde o material didático a ser trabalhado nas áreas de conhecimento 
até as formas e instrumentos de avaliação da aprendizagem, responsabilizandose ainda pela formação e acompanhamento dos alunos e OAs. Estes, por sua vez, acompanhavam os discentes em suas turmas, cuidando da realização cotidiana das atividades previstas no Moodle, bem como das práticas educativas/seminários temáticos, além dos estágios. Juntamente com os professores, os OAs participavam dos processos de avaliação.

O curso contava ainda com uma coordenação e uma coordenação adjunta. Havia uma equipe de oito profissionais de apoio tecnológico, para manutenção do ambiente e da página. Os professores especialistas em cada uma das áreas de conhecimento atendiam, sempre, em equipes de no mínimo três docentes, de modo que cada um pudesse acompanhar cinco turmas, num total de 90 a 100 alunos e cinco OAs. Eram previstos, para cada área de conhecimento do curso, encontros "presenciais" síncronos (com uso de videoconferência). E, ainda, um encontro presencial, no final de cada semestre, para que os professores da UFMT pudessem atender aos alunos nos polos em solo japonês.

Para esta pesquisa, a área de conhecimento trabalhada foi a de linguagens, que se subdividiu em Linguagem e Pensamento I e II, Linguagens Artísticas I e II, Literatura Infantil e Linguagem Corporal, num total de 490 horas, além das 100 horas de estágio. A área de conhecimento pesquisada foi organizada seguindo calendário semanal, que contou, em sua consecução, 12 semanas. Os recursos disponíveis no ambiente foram: na gestão de conteúdos: 15 textos em formato pdf, 6 arquivos para informações, orientações para a produção de áudio e/ou vídeo, apresentações em formato de páginas HTML, 8 arquivos multimídia láudio e vídeo), 9 apresentações multimídia (slides); recursos para a interação e comunicação: 8 fóruns de discussão em níveis e assuntos distintos sobre a área de conhecimento, 10 atividades com envio de arquivo - dois entre eles foram produção de vídeo pelos alunos -, 5 lições com informações multimídia.

A pesquisa foi realizada na perspectiva qualitativa (Santos Filho; Gamboa, 2001) com metodologia de estudo de caso. (Yin, 2010)

A decisão pela análise com base em "estudo de caso" teve como principal fator considerar os "relatórios de atividades" como possíveis instrumentos para o acompanhamento da participação e interação dos sujeitos em AVA, em razão da experiência institucional com a EaD e, ao mesmo tempo, a experiência com o uso mais intenso das TICs.

No caso das múltiplas linguagens, oito professores desenvolveram o trabalho da formação; destes, cinco eram doutores e três, mestres. Cinco deles eram oriundos do Instituto de linguagens (IL); um, do IE (Instituto de Educação); e o outro compunha a equipe de orientadores. Todos tinham experiência de, no mínimo, dez anos de atuação no ensino superior, sendo que dois possuíam domínio expressivo de uso das TICs e do trabalho com a EaD, fator que, sem dúvida, fortaleceu o grupo no desenvolvimento de seu trabalho. Outro dado importante: a equipe de professores que participou do acompanhamento dos alunos junto aos orientadores foi a mesma 
que elaborou o material didático impresso da área da linguagem para o curso. Esta equipe trabalhou com um projeto de formação significativo, justamente por ter se apropriado não só dos princípios que regiam o PPP do curso, como condição para elaborar o material didático impresso, como da elaboração do guia didático disposto no Moodle. Por conhecerem profundamente os conceitos a serem trabalhados na formação, constituíram "caminhos" e processos de estudos em que os estudantes participaram ativamente, mesmo com um período estendido de trabalho no AVA I12 semanas); os relatórios de atividades assim o demonstravam quando comparados com outras áreas de conhecimento que compunham o currículo do curso.

Sobre os relatórios de atividades, foram observados, num primeiro momento, o número de acessos das diferentes turmas com seus respectivos orientadores e professores. Com essas informações, considerando a necessidade de trabalhar com uma área de conhecimento já concluída, delimitou-se o campo da investigação.

Como critério de seleção dos sujeitos, a base foi os relatórios de atividades, considerando professores e OAs com maiores e menores índices quantitativos de acesso ao ambiente. Na estatística, selecionou-se turma a turma o seu respectivo professor e orientador. Esse trabalho de busca tinha por objetivo identificar o número de participação de cada um deles na turma que acompanhavam.

De posse dos dados obtidos pelos relatórios e com o critério de maior e menor número de acesso ao ambiente, a hipótese era a de que, quanto maior a participação do professor e orientador, maior seria a participação dos alunos.

Com a seleção das turmas, imediatamente também o foram os orientadores acadêmicos e professores especialistas, como consequência do processo de acompanhamento. Posteriormente à seleção dos sujeitos - no caso, 2 professores e 2 orientadores -, realizaram-se entrevistas, de modo que as informações dos relatórios pudessem ser melhor qualificadas. 0 período de coleta dos dados ocorreu entre os dias 30 de setembro e 20 de dezembro de 2011, e as entrevistas nos meses de fevereiro e março de 2012.

Antes de passar aos resultados da análise, importante destacar que os alunos do curso, por sua vez, evidenciam conjunto muito diverso em relação à naturalidade, faixa etária, formação anterior, condições de trabalho, acesso e familiaridade no uso das TICs. Aproximadamente $70 \%$ dos alunos eram professores de escolas brasileiras. Os demais profissionais, inclusive estrangeiros ${ }^{2}$, podiam atuar em Organizações Não Governamentais (ONGs) ou em escolas japonesas, como "mediadores culturais" junto a crianças brasileiras com dificuldades para seguir os estudos no sistema escolar japonês. Quase 60\% deles já possuíam diploma de nível superior, com formações em engenharias, ciências da saúde, biológicas ou bacharelados.

A maior parte, em razão da situação de migrante e do propósito de manter contato com familiares no Brasil, já tinha bastante familiaridade com o uso das TICs. Este

2. São dez alunos estrangeiros, entre japoneses, peruanos, paraguaios, bolivianos e argentinos, todos fluentes no idioma português. 
fator influenciou muito a maneira pela qual o trabalho com o Moodle foi desenvolvido no curso: com participação intensa dos alunos.

\section{Sobre o trabalho docente e as novas apropriações tecnológicas}

No caso do curso em pauta, com base nas respostas obtidas, os professores e OAs estimaram trabalhar no e com o Moodle entre 25 a 30 horas, distribuídas ao longo de uma semana, com acesso diário ao ambiente. Conforme observado por Silva, Alonso e Maciel (2012), embora com espaço físico específico de trabalho na UFMT, a maior parte dos acessos teve origem nas residências desses profissionais. 0 espaço institucional foi utilizado, preferencialmente, para a formação e reuniões pedagógicas. Então, o trabalho da formação não se reduzia ao AVA, ele se estendia às reuniões pedagógicas, à formação e, em muitos momentos, como no caso dos estágios, a encontros mais pontuais para verificação de casos específicos de alunos ou grupos deles, entre OAs e professores. De fato, a contabilização de todas essas horas extrapola, substancialmente, o previsto, por exemplo, para a preparação e a execução de uma disciplina com a mesma carga horária de outra que não usa AVA. Isso faz supor que o trabalho em rede, além de configurações específicas para ser "entregue" ao estudante, traz implicações que se estendem ao cotidiano dos envolvidos nesse processo, alheios ao fazer mais "clássico" do ensinar. Não se trata apenas de "dar aulas", mas de aquisições profissionais que se espraiam em vários âmbitos do técnico, do uso de recursos pouco conhecidos que geram demandas e expectativas de participação e interação, e do acompanhar e avaliar processos e procedimentos pouco usuais nas instituições de ensino superior, em razão, sobretudo, da mediatização e das mediações que se impõem com uso de AVA e TIC.

Tendo em vista os contornos do presente artigo, será exposta aqui parte das possibilidades de análise que o trabalho de coleta de dados encerrou, mesmo porque foram aquelas que mais se fizeram notar na pesquisa e que denotam duas dimensões do problema: como o uso dos AVAs/Moodle implica reconstituições do trabalho docente, e como isso afeta ou o influencia no sentido de intensificá-lo.

Por ser um curso muito "tecnologizado", tendo em conta a clientela e os diferentes espaços geográficos que envolviam a experiência, professores e orientadores, ademais de trabalhar na organização didático-pedagógica da formação, foram instados a dominar processos tecnológicos pouco conhecidos em suas vivências. Não se trata apenas de usar um ou outro recurso de AVA, mas de dar sentido e significado a eles, considerando a participação e a interação como base de um processo que fomente interatividade; portanto, aprendizagem.

$\mathrm{Na}$ "leitura" dos relatórios de atividades, foram perceptíveis curvas crescentes de participação na medida em que foram disponibilizados recursos em que a atuação 
do professor e orientador é necessária para o cumprimento de determinados objetivos de formação, como é o caso de fóruns, chats e wikis. A depender ainda da natureza das atividades de formação, foi possível verificar implicações de tempo e de demandas pelos alunos, como no caso do acompanhamento de projetos de estágio, que intensificam sobremaneira a necessidade de contato permanente e qualificado do professor, do orientador e dos estudantes. Assim, o cumprimento de objetivos de formação, quando direcionados à maior participação dos estudantes, redunda num sobretrabalho para professores e orientadores difícil de suportar, segundo depoimento de um dos docentes, cujo relatório apontava participação bem acima da média dos demais. Como afirmado por ele, "isso demanda estar conectado praticamente todo o tempo em que estamos trabalhando com uma área de conhecimento". (D. 2)

A necessidade de "estar conectado", de forma que o diálogo possa ocorrer durante a formação, faz com que os atores nela envolvidos participem, progressivamente, de um ato pouco conhecido e decodificado mais pelos significados culturais nele identificados do que pelo próprio desígnio educativo/formativo aí implícito. 0 estranhamento frente à situação do diálogo de um "curso" e não de uma rede social, por exemplo, expõem esses atores a frequentes atualizações de seus papéis, já que a relação da formação não é tão "horizontal" como a que se pretende em outros "lugares" do mundo virtual. Para o orientador que fica e age entre o professor e 0 aluno, o diálogo qualificado está mais na relação cotidiana que estabelece com os alunos de sua turma do que propriamente naquilo que se desenvolve do ponto de vista curricular. "Mais que o currículo, o conteúdo, as atividades de ensino, a questão que se coloca para nós, orientadores, é o do como fazer "girar" a formação numa relação em que a autoria não é nossa" (OA 3). 0 professor, mesmo na perspectiva de uso mais intenso das TICs, e na possibilidade de se instaurarem processos mais colaborativos de trabalho, ainda é responsabilizado pelo sucesso do projeto pedagógico; é nele que as expectativas da formação estão postas. Com isso, o denominado AVA é frequentemente "burlado". Várias foram as situações em que estudantes e orientadores acadêmicos recorriam a outros meios não presentes no AVA como Skype e MSN para interagirem. Como afirmado por Toschi (2010), as TICs envolvem os sujeitos em outras maneiras de organizar as informações e navegar pelos oceanos da internet.

0 principal elemento a ser considerado sobre as crescentes demandas geradas num processo de intensa comunicação entre os atores de uma formação é reconhecer, primeiramente, os limites postos por um AVA/Moodle. Por mais que as customizações ocorram, o dia a dia da formação fornece e constitui mediações e interações alheias a ele, fazendo com que os envolvidos nela busquem alternativas outras, compondo caminhos e soluções próprias e individualizadas. Qual o problema gerado por isso? Por constituir o "espaço" da formação, o registro de todas as atividades no Moodle é condição essencial; várias informações estavam, no entanto, alocadas ou "espalhadas" em outros espaços, resultando no seu "empobrecimento". 
Ao se trabalhar no limite do que é posto como institucional levidentemente que, num curso de graduação, não haveria como minimizar issol, a dispersão das informações seria um problema, cabendo às equipes aí envolvidas o trabalho de busca e de complementação dos registros. Daí que este processo: o da demanda por mais e mais mediação e interação, com a consequente busca de soluções para isso, acabou por intensificar, como fator secundário, mas tão importante quanto o antes mencionado, o trabalho docente, seja aquele envolvendo o professor, seja os OAs.

No curso em pauta, uma das soluções foi agregar ao Moodle outros recursos e, nas atividades de fóruns, chats, wikis, entre outras, gravar e fazer edições do que fora publicado, criando acervos por assunto em cada uma das áreas de conhecimento. A dificuldade é que nem sempre as equipes que atuam por meio de AVA estão implicadas num trabalho mais cooperativo que permita a busca de alternativas que apoiem o desenvolvimento pedagógico de um curso de natureza colaborativa. De toda maneira, nos relatos dos professores e orientadores, foi comum a reflexão sobre o modo como o trabalho com as TICs/AVA implicaram mudanças em suas práticas pedagógicas.

Para Peixoto (2009), dos profissionais que se envolvem em experiências com a EaD, em que as mediações ocorram por meio das TICs, exigem-se procedimentos de trabalho que necessariamente explicitem "objetivos, seleção, estruturação e acessibilidade de conteúdos, apoio à aprendizagem, mediação dos conteúdos, escolha de mídias [...]" (Peixoto, 2009, p. 94). Na perspectiva da autora, "esses procedimentos foram banalizados, sendo raramente questionados ou assumidos como responsabilidade coletiva de quem concebe e executa os programas educacionais". Daí que o trabalho nessas experimentações de EaD seriam oportunidades significativas para um repensar a prática pedagógica dos professores.

Isso, contudo, não acontece, como os próprios professores e orientadores reconheceram, sem que ocorram mais atividades de trabalho em grupo, o uso de recursos com os quais têm de se familiarizar e, sobretudo, sem que aconteçam mudanças radicais na forma pela qual organizam e sistematizam os processos do ensinar e aprender. Para além de uma capacitação continuada, esses profissionais indicaram que, em suas práticas, a incorporação das TICs configurou sobrecarga de trabalho e de responsabilidade, coincidindo com o observado por Peixoto (2009):

Assim, se um professor passa a trabalhar num contexto de EaD, isso requer outro horário de trabalho, disponibilidade para acompanhamento virtual, outro tipo de contato com os alunos e, especialmente, outra representação de sua ação e do que ela pode trazer a eles. Dessa forma a apropriação pedagógica das TICs pode conduzir o professor a um questionamento metodológico essencial, ou seja, levar à problematização de representações cristalizadas e práticas triviais, banalizadas pelo uso repetido e com base em fundamentos pouco esclarecidos. (Peixoto, 2009, p. 94) 
Na pesquisa, também o orientador, por sua origem profissional e por atuar numa perspectiva docente, comungava dos mesmos dilemas e ressignificações em sua prática pedagógica.

0 discurso da "revisão", do reolhar sobre o trabalho e as práticas nele instauradas foi constante, aproximando professores e orientadores, gerando discussão sobre a necessidade de que, institucionalmente, esse trabalho fosse reconhecido. Nessa dimensão, a institucional, dois são os elementos apontados pelos sujeitos: o desejo de que a EaD seja incorporada aos cotidianos profissionais como prática diferenciada, justamente por gerar sobrecarga de trabalho quando processos de mediação, interação e interatividade são priorizados; e, no caso do orientador, o reconhecimento de que seu trabalho teria, de fato e direito, natureza docente. Impossível, na visão dos entrevistados, afirmar, por exemplo, que o acompanhamento de um aluno não seja trabalho da ordem ou da dimensão da docência.

Os sujeitos da pesquisa discorreram ainda sobre a percepção do aluno, nesse processo, como bastante vinculada ao interagir na "presença" ou do professor, ou do orientador, entendo-a como forte indício de interação. Para os sujeitos, isso se justificaria pela pouca experiência nesse campo e pela concepção de ensino/ aprendizagem perpassada pela noção de que a presença de um "professor" seria fundamental para que os conhecimentos aí circulassem. Então, além do sobretrabalho gerado pela organização do que seria a docência com uso das TICs, haveria de se "produzir" uma autonomia pelos alunos que caracterizasse o sentido de uma comunidade. Claro que, com o tempo, isso vai sendo fomentado, segundo os mesmos sujeitos, mas consequência sempre, e no caso estudado, de um árduo trabalho de "presença inicial", passando para maior protagonismo dos alunos. Essas "criações", conforme os relatos, suscitariam sempre mais ações no AVA.

Até o momento, o que foi observado é uma excitação pela experimentação, por se organizar processos de trabalho docentes pouco conhecidos, provocativoprovocadores em sua formulação, e a descoberta das potencialidades dos recursos interacionais dispostos num AVA, levando à percepção ou à sensação, como antes mencionado, de autonomia. Ao mesmo tempo, o desalento pelo volume de trabalho despendido ao se tornar um "docente on line", sem que isso tenha eco nas instituições que ofertam a EaD. Difícil situação essa do "teletrabalho", mas, sem dúvida, pauta importante na e para a institucionalização da modalidade de EaD nas Ifes.

\section{Algumas anotações finais}

Como pôde ser observado, a problemática relacionada à normalização do trabalho docente na EaD com uso intenso das TICs é campo ainda pouco explorado, denotando necessidade premente se compreender em que redundam a participação 
e a interação subsumidas nos AVAs, evidenciando que nesse processo o trabalho docente é influenciado, sobremaneira, em várias dimensões e níveis.

O significado, a codificação de novas linguagens, a compreensão do que seja a mediação por meio de tecnologias, a formação das equipes e a forma pela qual se organizam os hábitos de trabalho, entre outros elementos, vão ocupando os espaços organizacionais convertendo-os em fazeres que, por não serem comuns, não são reconhecidos. Se as práticas pedagógicas são agora influenciadas no sentido de dinamizá-las, inclusive no ensino presencial, e se há o entusiasmo pela experimentação, surge, ao mesmo tempo, o incômodo do sobretrabalho, da intensificação dele e de se conviver com relações pouco esclarecidas, como no caso dos OAs (tutor), que trabalham como docentes, mas com negação dessa condição, inclusive por parte dos organismos financiadores dos programas e projetos de EaD.

A expansão da EaD, com a consequente expansão do uso de AVA, poderia estimular as instituições de ensino superior a inovações importantes do ponto de vista pedagógico, como constatado pelos sujeitos pesquisados. No entanto, as promessas vão pouco a pouco sendo limitadas e conformadas pelo cotidiano laboral. As implicações do participar, interagir e construir colaborativamente são minimizadas na tentativa de melhor compreender, por enquanto, o alcance, ou não, dos recursos comunicacionais aí presentes, e pouco disso é tomado institucionalmente. A descoberta de como incorporar as possibilidades de uso das TICs à formação é um desafio, já que seu caráter comunicativo altera esse processo, alterando consequentemente o trabalho docente não no sentido de desqualificá-lo, como visto nos relatos, mas na capacidade de criação que se exige, na medida em que impõe outras e novas relações entre os envolvidos na formação.

0 estudo, mesmo sem investigar os alunos, expõe a dificuldade de se trabalhar com os recursos disponíveis no Moodle, por exemplo, que poderiam subsidiar a tomada de decisões pedagógicas no transcorrer da formação, com investimento importante na criação de dinâmicas de trabalho participativas e interativas, condição "roubada" quando do excesso de trabalho originado pela demanda do interagir em conexão.

Na esteira das discussões propostas por Tezanos (2009), uma das dimensões presentes e importantes sobre o trabalho é a que se refere à sua precarização. Mais e mais, nas "sociedades tecnológicas", este se precarizaria por conta de sua intensificação, resultado, entre outros, da complexificação, que tem como um dos ingredientes as TICs.

Para Souza (2009), a precarização do trabalho docente se expressa na flexibilização e desregulamentação da legislação sobre a profissão (como é o caso do tutor), para dar sentido às propostas de mercado. Nesse viés, as competências necessárias para se trabalhar com as TICs apresentam-se como mais um atributo/qualidade a ser promovida no trabalho do docente, agudizando as fragilidades e precariedades quando do uso dos artefatos técnicos e tecnológicos, impondo dinâmicas pouco 
conhecidas pelos professores.

Se as práticas pedagógicas são renovadas pela inserção das TICs, gerando certo "frisson" entre os que com ela trabalham, por conta da sensação de experimentações possíveis de serem realizadas no cotidiano "apertado" de seus afazeres, que não sejam elas, as TICs e a EaD, os motes para se concretizar a intensificação e precarização antes mencionadas.

\section{Referências}

ALONSO, Katia Morosov. Educação a distância e tutoria: anotações sobre o trabalho docente. In: ALONSO, Katia Morosov; RODRIGUES, Rosângela Schwarz; BARBOSA, Joaquim Gonçalves. Educação a distância - práticas, reflexões e cenários plurais. Cuiabá: Central de Texto: EdUFMT, 2010, p. 81-98.

BELLONI, Maria Luíza. Educação a Distância. Campinas: Autores Associados, 1999. BLIKSTEIN, Paulo; ZUFFO, Marcelo Knörick. As sereias do ensino eletrônico. In: SILVA, Marco. (Org.). Educação online. São Paulo: Loyola, 2003. p. 23-38.

BRASIL. Referencias de Qualidade para Cursos Superiores a Distância. Disponível em: $<$ http://portal.mec.gov.br/seed/arquivos/pdf/legislacao/refead1.pdf>. Acesso em: 21 ago. 2011.

COVEZZI, Marinete; OLIVEIRA, Anderson Castro Soares de; SANTOS, Sandro Aparecido Lima dos. (2011). Imigrantes brasileiros no Japão: expectativas, estratégias e reorientações no mercado de trabalho. XXVIII Congresso Internacional da ALAS - 6 a 11 de setembro/2011, Recife: UFPE. Disponível em: <http://www.sistemasmart. com.br/alas/arquivos/18_8_2011_0_25_37.pdf>. Acesso em: 10 jan. 2012.

SILVA, Danilo Garcia da; ALONSO, Katia Morosov; MACIEL, Cristiano. Os ambientes virtuais de aprendizagem, participação e interação, ou sobre o muito a caminhar. PERSPECTIVA, Florianópolis, UFSC, v. 30, n. 1, 77-104, jan./abr. 2012.

MILL, Daniel; RIBEIRO, Luis Roberto de Camargo; OLIVEIRA, Marcia Rosenfeld Gomes (Org.). Polidocência na educação a distância: múltiplos enfoques. São Carlos: EdUFSCar, 2010.

PEIXOTO, Joana. A concepção de dispositivo pedagógico que integrem as TIC. InterAção, Goiânia, UFG, 34 (1): 89-104, jan./jun. 2009.

PROJETO POLÍTICO PEDAGOGICO DO CURSO DE PEDAGOGIA ACORDO BRASIL/ JAPÃO. Mato Grosso: UFMT, 2009. Disponível em:<www.nead.ufmt.br/japao>. Acesso em: 24 maio 2012.

SANTAELLA, Lucia. Navegar no ciberespaço: o perfil cognitivo do leitor imersivo. São Paulo: Paullus, 2004.

SANTOS FILHO, José Camilo dos; GAMBOA, Silvio Sánchez. Pesquisa educacional: quantidade-qualidade. 4. ed. São Paulo: Cortez, 2001. 
SCHLEMMER, Eliane. Metodologias para Educação a Distância no Contexto da Formação de Comunidades Virtuais de Aprendizagem. In: BARBOSA, R. M. Ambientes Virtuais de Aprendizagem. Porto Alegre: Artmed, 2005.

SOUZA, Ana. Neri. As formas Atuais de Modernização do Trabalho de Professores: individualização e precarização? In: GARCIA, Dirce Maria Falconi; CECILÍo, Sálua. (Org.) Formação e Profissão Docente em Tempos Digitais. Campinas, Editora Alínea, 2009, p. 91-116.

TOSCHI, Mirza Seabra. A dupla mediação no processo pedagógico. In: TOSCHI, Mirza Seabra. (Org.) Leitura na tela - da mesmice à inovação. Goiânia: Ed. da PUC Goiás, 2010, p. 171-179.

TEZANOS, José Félix. La sociedad dividida - Estructuras de clases y desigualdades en las sociedades tecnológicas. Madrid: Biblioteca Nueva, 2009.

TÜRCKE, Christoph. A Sociedade excitada - filosofia da sensação. Trad. Antonio A. S. Zuin; Fabio A. Durão; Francisco C. Fontanella; Mario Frungillo. Campinas: Editora da UNICAMP, 2010.

YIN, Robert K. Estudo de Caso: planejamento e métodos. Trad. Ana Trorel. São Paulo: Bookman Companhia, 2010.

Recebido em outubro de 2012

Aprovado em julho de 2013

Katia Morosov Alonso é doutora em educação pela Universidade Estadual de Campinas e professora adjunta da Universidade Federal de Mato Grosso. E-mail: katia.ufmt@gmail.com

Danilo Garcia da Silva é doutorando em educação na linha de pesquisa Organização Escolar, Formação e Práticas Pedagógicas, do Instituto de Educação da Universidade Federal de Mato Grosso. E-mail: danilogsilvasQagmail.com 